IdeAs

Idées d'Amériques

$14 \mid 2019$

Populismes dans les Amériques

\title{
Entrevista com Tamis Parron e Leonardo Marques
}

\section{Angélica Müller}

\section{(2) OpenEdition}

Journals

Edição electrónica

URL: http://journals.openedition.org/ideas/6636

DOI: 10.4000/ideas.6636

ISSN: 1950-5701

\section{Editora}

Institut des Amériques

\section{Refêrencia eletrónica}

Angélica Müller, «Entrevista com Tamis Parron e Leonardo Marques », IdeAs [Online], 14 | 2019, posto online em 01 outubro 2019, consultado o 09 novembro 2019. URL : http://journals.openedition.org/ ideas/6636 ; DOI : 10.4000/ideas.6636

Este documento foi criado de forma automática no dia 9 novembro 2019

\section{(c) (i) (9)}

IdeAs - Idées d'Amériques est mis à disposition selon les termes de la licence Creative Commons Attribution - Pas d'Utilisation Commerciale - Pas de Modification 4.0 International. 


\title{
Entrevista com Tamis Parron e Leonardo Marques
}

\author{
Angélica Müller
}

1 Em maio de 2019, a Universidade Federal Fluminense (UFF) localizada na cidade de Niterói no estado do Rio de Janeiro (Brasil), inaugurou o Centro de Desigualdades Globais recebendo a biblioteca, os projetos e a herança intelectual do Centro Fernand Braudel, localizado na Universidade de Binghamton. Na cabeça deste projeto estão dois jovens historiadores da UFF,

2 Tamis Parron e Leonardo Marques. Parron é professor de história do Brasil Império. Doutorou-se na Universidade de São Paulo (2015) e realizou estágio pós doutoral na Harvard University (2016). Em 2012, ganhou o maior prêmio da literatura no Brasil, o Jabuti, pelo livro “A política da escravidão no Império do Brasil, 1826-1865”, fruto do seu trabalho de mestrado. Leonardo Marques é professor de história da América Colonial. Doutorou-se na Emory University (2013) e realizou estágio pós doutoral na Universidade de São Paulo (2015). Dentre os seus trabalhos destaca-se o livro "The United States and the Transatlantic Slave Trade to the Americas", publicado pela Yale University Press (2016).

ANgÉLICA MülleR: Qual foi o contexto da construção do Centro Fernand Braudel na Universidade de Binghamton, em 1976?

Tamis Parron e Leonardo Marques: O CFB foi uma resposta institucional e científica inovadora aos desafios globais que a crise do capitalismo impôs à governança mundial na década de 1970. Uma série de processos contraditórios vinham se formando no seio da ordem mundial do pós-guerra, como o fim da reconstrução europeia, a descolonização afro-asiática e a crise ambiental da chamada "Grande Aceleração". Com o tempo, esses processos se articularam com o Choque do Petróleo, a elevação de preços do petróleo pela OPEP. A crise foi gigantesca e permanente, pois o petróleo era (e é) uma mercadoria elementar que integra as principais cadeias produtivas globais, regulando o custo geral de produção de mercadorias e o custo geral de reprodução da mão de obra no mundo inteiro. A combinação imprevista desses eventos elevou o custo do dinheiro, dos insumos e do trabalho do dia para a 
noite. Deu um banho de água fria no American Way of Life e criou pressões competitivas globais que redefiniram padrões de acumulação de capital no mundo. Curiosamente, a crise dos anos 1970 desaguou em dois processos mundiais aparentemente contraditórios, mas no fundo complementares: o neoliberalismo no mundo atlântico e o arranque produtivo do Indo-Pacífico (ou o deslocamento do eixo dinâmico dos processos produtivos industriais globais do Atlântico para o IndoPacífico).

Essas transformações - que, aliás, estão na gênese das desigualdades crescentes que abalam as democracias hoje - é que motivaram a criação do CFB na década de 1970. Pense que na época a visão de mundo mais consensualmente aceita era a teoria da modernização, formulada por Walt Rostow, consultor da política externa dos EUA (em particular, de Eisenhower) e patrocinada pelo Departamento de Estado norteamericano. Rostow dizia que a diferença na trajetória econômica entre países ricos do Ocidente e os demais países se devia ao desenho institucional das nações e que bastaria aos países pobres imitar as receitas dos países ricos para que seu bolo econômico também crescesse.

Para voltar à sua pergunta, a crise generalizada dos anos 1970 e a dissolução da visão de mundo da teoria da modernização criaram o estímulo para o surgimento do CFB, um espaço de pesquisa concebido para explicar mudanças sociais de larga escala na longa duração.

Assim, quando Terence Hopkins e Immanuel Wallerstein fundaram o CFB em 1976, o seu primeiro desafio científico foi entender as transformações mundiais do capitalismo nos anos 1970 não só como o resultado parcial de causas complexas do tempo presente, que era o que fazia a maioria dos melhores analistas da época, mas como a materialização historicamente específica de processos que remontavam, digamos, às origens da História Moderna, como a expressão particular de uma história muito mais profunda e plurissecular.

A. M.: Por que homenagear o importante historiador francês?

T.P., L. M.: A amizade de Wallerstein e Braudel nasceu quando o Wallerstein começou a enviar para Braudel os capítulos manuscritos do primeiro volume do que viria a ser o seu magnum opus, O sistema mundial moderno (1974). Na época, Braudel estava escrevendo Civilização material, economia e capitalismo, outra interpretação de fôlego do capitalismo, e ele leu com muito entusiasmo a produção ambiciosa de um acadêmico norte-americano quase trinta anos mais jovem que ele. Dali nasceu uma troca intelectual rica, uma influência recíproca genuína, um daqueles diálogos que são, ao mesmo tempo, o resultado e a causa da grandeza intelectual dos interlocutores.

Graças à amizade que fizeram, Wallerstein trabalhou com Braudel durante um ano na École des Hautes Études en Sciences Sociales, em Paris, logo depois da publicação do primeiro volume do seu livro, O sistema mundial moderno. Quando ele voltou para os Estados Unidos, Terence Hopkins, que fora seu ex-colega, aluno e professor na Universidade de Columbia, tinha conseguido a autorização para abrir um centro de ciência social histórica sobre o capitalismo na Universidade de Binghamton. Wallerstein se juntou à iniciativa, e aí a homenagem ao Braudel pareceu natural e oportuna. Afinal de contas, Braudel era o intelectual mais bem aparelhado para 
atender à demanda por uma ciência social capaz de explicar o mundo como uma totalidade processual.

A gente pode dar um passo adiante na análise e verificar que Braudel influenciou até mesmo as noções de espaço e tempo na obra de Wallerstein. De fato, Wallerstein levou a sério a noção braudeliana de que a história é o campo da síntese das outras ciências sociais graças à dialética das durações: a longa duração, o recitativo de conjuntura, os eventos de curta duração. Ao passo que economistas, cientistas políticos e sociólogos lidam com tempos mais curtos, e os antropólogos com o mais longo, a história realizaria a reunificação do saber social por entender a mudança social como resultante da interação dialética dos diversos tempos constitutivos da vida humana. Braudel foi de fato muito agudo e sagaz na relevância causal que atribuiu aos tempos sociais. Antes dele, outros acadêmicos franceses, como François Simiand e Ernest Labrousse, já tinham entendido que qualquer evento da vida social nasce do concurso mais ou menos contingente de causas independentes, que solicita não um antecedente, mas uma pluralidade articulada de precedentes. Braudel refinou essa percepção dando a essa série de causas independentes camadas estratigráficas de durações temporais. Wallerstein aprendeu muito com isso.

Braudel não legou a Wallerstein só uma visão complexa da pluralidade do tempo social. Ele ainda lhe permitiu refinar a noção de espaço histórico. Braudel sempre frisou o fato de que o espaço através do qual as atividades humanas se formam não se reduz à simples territorialidade homogênea dos Estados nacionais. Wallerstein soube incorporar essa percepção e levá-la a seu corolário lógico. Ele argumentou que o coração do capitalismo histórico deve a sua vida, o seu ritmo e a sua pulsação a uma tensão espacial primária, uma contradição entre a espacialidade zonal da política (ou do Estado) e a espacialidade reticular das atividades econômicas. Graças à sensibilidade espacial de Braudel, Wallerstein nos faz ver que o capitalismo histórico é um sistema de acumulação que nasce, se desenvolve e entra em crises manipulando as diferentes territorialidades dos movimentos sociais, das decisões políticas e dos fluxos de capital.

É importante, por fim, lembrar que Wallerstein também influenciou Braudel. A bem da verdade, parece que Braudel não sabia ainda muito bem como encaminhar seu argumento em Civilização material, economia e capitalismo. $O$ terceiro volume foi escrito depois do contato epistolar com Wallerstein e, principalmente, depois da estadia de Wallerstein na École des hautes études en sciences sociales, no ano acadêmico de 1975-1976. O próprio Braudel reconheceu, no terceiro volume (que é de 1979) que o trabalho de Wallerstein o ajudou a entender melhor sua própria interpretação.

A. M.: Como vocês entraram em contato com o Centro?

T.P., L. M.: Um diálogo muito profícuo, envolvendo um número significativo de historiadores brasileiros, foi construído ao longo das últimas duas décadas em torno do conceito de "segunda escravidão", originalmente lançado por Dale Tomich (figura central na história do Centro Fernand Braudel) no fim da década de 1980. A ideia originalmente proposta por Tomich é relativamente simples: o século XIX, era de expansão do abolicionismo, foi também marcado pela expansão da escravidão em novos espaços, nomeadamente o oeste de Cuba, o Vale do Paraíba, no Brasil, e o sul dos Estados Unidos. Com este ponto de partida, um conjunto de pesquisadores tem 
explorado os múltiplos condicionamentos entre as diferentes sociedades escravistas do oitocentos e seu lugar na economia mundial capitalista. Uma das primeiras pesquisas coletivas surgidas desse movimento foi uma análise comparada da paisagem e arquitetura da segunda escravidão com Rafael Marquese, os cubanos Reinaldo Funes e Carlos Venegas, além do próprio Tomich. Nos anos seguintes, Marquese e outros historiadores brasileiros como Ricardo Salles, Mariana Muaze, dentre outros, expandiram os debates em torno do conceito, não raro com a participação dos outros membros da rede da segunda escravidão, o que invariavelmente levou a debates críticos em torno de toda a tradição intelectual que estava subjacente ao conceito. Nesse contexto foi fundado o Lab-Mundi por Rafael Marquese e João Paulo Pimenta, em 2013, na Universidade de São Paulo, cuja intenção explícita é explorar a história do Brasil em suas relações com o sistema mundial capitalista. Desde o início, o laboratório contou com três dos membros fundadores do Centro UFF de Desigualdades Globais: Douglas Leite, Leonardo Marques e Tâmis Parron.

Em suma, vínhamos travando um intenso diálogo não apenas entre nós, mas com os próprios membros do Centro Fernand Braudel, especialmente Dale Tomich. Em 2017, tivemos a felicidade de estarmos os três trabalhando na Universidade Federal Fluminense (Douglas é membro do Departamento de Direito desde 2010, Leonardo entrou para o Instituto de História em 2015, seguido por Tâmis dois anos depois). Considerando nossas afinidades intelectuais, rapidamente decidimos que deveríamos formar algum grupo de pesquisa na universidade. Conforme conversávamos com colegas de diferentes disciplinas, soubemos da decisão da direção do Centro Fernand Braudel de encerrar as suas atividades. Considerando nosso longo diálogo com o CFB, demos início a uma série de conversas com Tomich e Richard Lee, atual diretor do Centro, para discutir as possibilidades de herdarmos os recursos acumulados pelo CFB ao longo de meio século.

Com o apoio de muitas pessoas, de diferentes departamentos da UFF, e da própria Reitoria, conseguimos costurar um acordo que levará à transferência da enorme biblioteca de periódicos e toda a rede de contatos do Centro Fernand Braudel para o recém-fundado Centro UFF sobre Desigualdades Globais.

A. м.: Depois de mais de 40 anos de funcionamento na Universidade de Binghamton, os arquivos serão doados para o novo Centro UFF sobre Desigualdades Globais. O que significa esta mudança? Mais do que isso: o que significa uma mudança norte-sul?

T.P., L. M.: Você tocou num ponto importante: as relações norte-sul no mundo contemporâneo. Em geral, achamos que essas relações se restringem à circulação de bens, pessoas e capital. Na verdade, elas também englobam ideias e trocas acadêmicas. Infelizmente, a noção de troca desigual se aplica não só à economia mundial, mas também à cultura acadêmica.

Como você sabe, a troca desigual é aquela em que se realiza o aparente intercâmbio de equivalentes, mas na qual, na verdade, há ganhos e perdas diferenciais para os envolvidos. É exatamente isso o que ocorre na academia em nível mundial. Na maior parte das vezes, a comunidade científica internacional permite que cientistas sociais do Norte produzam conhecimento teórico, quadros conceituais, formulações abstratas. Quando dizemos "permite", queremos dizer "consome e divulga". Essa mesma comunidade, porém, reduz os pesquisadores do sul ao papel de fornecer dados 
empíricos e descrições particulares. Isto é, ignora sua produção teórica e cita no rodapé apenas a que aporta dados, fatos e eventos.

Quando você aperta para ver o que exatamente é o "norte", logo se torna claro que ele também é desigual: o norte são, fundamentalmente, as academias angloamericanas. É como se não houvesse vida inteligente no mundo para além da "vila" anglo-saxã.

Os autores da perspectiva do sistema-mundo sempre viram com muito ceticismo e crítica as trocas desiguais no plano material e simbólico da comunidade científica internacional. Se deixarmos Braudel de lado por um instante, além de inspirações óbvias como Marx, veremos que algumas das principais fontes intelectuais da perspectiva do sistema-mundo provieram de espaços ditos periféricos: a noção de centro e periferia, do argentino Raúl Prebisch; a noção de troca desigual, de Amir Samir e Arghiri Emmanuel; a dimensão internacional dos processos econômicos, da teoria da dependência; e o radicalismo do pensamento negro marxista, de C. L. R. James, Eric Williams e Frantz Fanon. Os autores da perspectiva do sistema-mundo, Wallerstein entre eles, rejeitaram o paroquialismo científico anglo-saxão, incorporando, em seu lugar, o conhecimento científico do sul ("sul" aqui é uma metáfora geográfica) não como repertório de dados e fatos, mas como uma tradição de saber social que também pode falar dos processos universais em pé de igualdade com pensadores do norte. Isso ficou evidente, também, na prática do CFB de convidar pesquisadores visitantes de fora dos circuitos tradicionais, como Aníbal Quijano e Walter Rodney, com a intenção não de sobrepor uma tradição à outra, que poderia levar a novos paroquialismos, e sim de quebrar os limites estabelecidos por trocas acadêmicas desiguais.

Que a UFF receba, desenvolva e reformule, conforme os desafios contemporâneos, a herança intelectual do CFB é algo extremamente consistente com a própria agenda intelectual, política e ideológica do CFB.

A. M.: Quais os projetos para o Centro em Niterói?

T.P., L. M.: O Centro UFF nasce com a missão de ser um polo produtor de conhecimento de ponta sobre o problema mais dramático do mundo contemporâneo: a difusão da desigualdade socioeconômica dentro de um mundo cada vez mais rico e integrado.

Como fazer isso? Nós seguimos três valores inegociáveis: interdisciplinaridade comparativa, conhecimento participativo e conceitos sensibilizadores. Vejamos um por um.

Até o momento, a produção científica sobre desigualdades tem sido quase um assunto privê da economia. O conhecimento obtido é de excelência, sem dúvida. Mas a maioria dos economistas, por formação, coloca a ênfase da análise nos tempos curtos e médios e enfoca nos fluxos de capital e pessoas. O Centro UFF, por sua vez, se propõe estudar processos que estão na base da acumulação assimétrica de capital olhando para relações estruturadas de poder, geopolítica, ecologia mundial, enfim para relações multidimensionais e espaço-temporalmente multiestratigráficas que determinam rendas diferenciais de modo mais complexo do que dão a entender noções como "produtividade", "vantagens comparativas" e "capital humano". 
Como fazer isso sem perpetuar as relações e estruturas de poder que produzem desigualdade no interior da própria produção do conhecimento? Aí entra o nosso segundo valor inegociável. O Centro UFF se apresenta como um espaço de conhecimento participativo. Vamos reunir acadêmicos, gestores de política pública e atores sociais tanto do Brasil como de outros países diante de um problema comum, para que possam criar e compartilhar ideias sobre como encontrar suas possíveis soluções.

As práticas da interdisciplinaridade comparativa e do conhecimento participativo vão levar a um novo enquadramento do problema da desigualdade e, a partir daí, à formulação de conceitos sensibilizadores, o nosso terceiro valor. Conceitos sensibilizadores são aqueles que desnaturalizam a maneira como vemos a reprodução da vida social. Atualmente, a maior parte dos conceitos mais usados para entender o mundo contemporâneo é moldada por interesses geopolíticos, pela lógica de empresas e pela linguagem do capital. O Centro UFF deve estimular uma revisão radical dessas noções e propor no lugar delas outras que despertem o ânimo para a ação.

Há algo de curioso nisso tudo. O Brasil é um país extremamente desigual, porém não possui uma boa teoria social sobre a desigualdade. 0 paradoxo do Brasil, se podemos dizer assim, é também o paradoxo do mundo contemporâneo. A nossa utopia científica é fornecer pontos de partida para reorganizar o nosso atual sistema de diagnósticos sobre o Brasil e o mundo contemporâneo. Uma sensibilização que desencadeie a convergência sinérgica de forças sociais distintas em torno de iniciativas comuns contra os efeitos disfuncionais das desigualdades globais.

A. M.: No seu famoso artigo sobre a longa duração publicado na revista dos Annales, em 1958, Braudel falava de uma crise das ciências humanas oprimidas pelo seu próprio progresso. Apelava, então, para a necessidade de um trabalho coletivo entre as ciências (tão cara aos Annales) e discutia a importância dos diferentes tempos para análise das estruturas históricas. Qual a atualidade das premissas levantadas por Braudel?

T.P., L. M.: Na década seguinte ao artigo clássico de Braudel, as ciências sociais passaram por transformações radicais trazidas pelas diferentes guinadas (linguística, cultural, etc.). Para além de uma certa angústia em torno de uma suposta impossibilidade de se escrever a história, que assolou parte do campo, historiadores responderam aos desafios trazidos por tais mudanças com um mergulho ainda mais intenso nos arquivos, com o desenvolvimento de importantes tradições historiográficas.

Uma das principais estratégias metodológicas empregadas por historiadores foi a redução da escala com a micro-história, que, no caso francês, se desenvolveu em contraposição direta ao legado do Braudel. Ao reduzir a escala de análise seria possível perceber os limites de grandes narrativas e compreender como estruturas operaram de modo distinto do que antes imaginado, além de permitir compreender as relações entre diferentes tempos, conexões que Braudel teria, aparentemente, negligenciado. Nesse sentido, parte desses trabalhos prometia realizar mais do que uma redução de escala; o objetivo era desenvolver um jogo de escalas que eventualmente retornasse ao processos macro-históricos. A ideia de que a compreensão de diferentes tempos era fundamental para a compreensão de estruturas históricas ainda estava presente. 
Mas aquele ponto de chegada revelou-se muito mais difícil de ser alcançado do que o anunciado. Com o mergulho intenso nos diferentes acervos documentais e a redução da escala de análise, as próprias perguntas de pesquisa passaram a ser crescentemente guiadas pelo arquivo, resultando em um conjunto de platitudes que foram travestidas de teoria, como bem apontou Gary Wilder: o estado nunca domina por completo, fenômenos históricos são mais complexos do que as suas representações abstratas, discursos e práticas nem sempre estão alinhados, o ser humano é sempre capaz de agir mesmo quando oprimido, e por aí vai. Não por acaso, o próprio conceito de capitalismo foi desaparecendo ou se restringindo a breves referências nas introduções e conclusões de livros de história.

O outro aspecto do ensaio clássico de Braudel que você levanta, a necessidade de um trabalho coletivo entre diferentes ciências, também foi, em parte, empobrecido por esses desenvolvimentos. Ao mesmo tempo que o mergulho nos arquivos fortaleceu a disciplina e a permitiu sobreviver ao longo do último meio século, acompanhada de algumas apropriações teórico-metodológicas de vertentes da antropologia, por exemplo, a possibilidade de um diálogo mais profundo entre diferentes disciplinas ficou muito restrita. A maior parte dos historiadores entrincheirou-se na própria disciplina. Para um exemplo do limite dos diálogos possíveis postulados por esse movimento, veja as considerações recentes de Giovanni Levi, que sugere que a microhistória e as histórias conectadas estariam ligadas à antropologia enquanto a famigerada global history estaria em sintonia com as "sínteses simplificadoras" da sociologia.

No entanto, uma tradição distinta emergiu a partir do diálogo original entre a segunda geração dos Annales e a perspectiva de sistemas-mundo. Concomitante ao desenvolvimento da micro-história nas décadas de 70 e 80, um conjunto de pesquisadores travou um diálogo crítico com o (e no interior do) Centro Fernand Braudel. Quando olhamos cuidadosamente para os trabalhos de Sidney Mintz, MichelRolph Trouillot, Eric Wolf, Philip McMichael e Dale Tomich, dentre outros, observamos que algumas das mesmas questões estão ali postuladas: a relação dinâmica entre as partes e o todo, entre o micro e o macro, entre as diferentes temporalidades da história. As respostas produzidas nesse contexto implodiram com divisões disciplinares, mostrando a riqueza de abordagens que atravessavam e combinavam os ganhos da história, antropologia, sociologia, geografia, economia, dentre outras disciplinas.

Qual é a atualidade das premissas originais de Braudel? Em um momento no qual se debate a possibilidade de se estabelecer uma nova categoria geológica - o antropoceno - para descrever o impacto das atividades humanas sobre o meio ambiente e a possibilidade de extinção da própria espécie em um futuro próximo, o trabalho coletivo entre diferentes ciências deixou de ser uma possibilidade para ser uma necessidade. Tais atividades humanas não são atemporais, mas produto de diferentes formas de organização econômica, política e sociocultural que se transformam através do tempo. Compreender tais transformações e, especificamente, o lugar do capitalismo enquanto sistema histórico (com todas as suas assimetrias em diferentes níveis) em tais desenvolvimentos é uma das tarefas mais urgentes da ciência contemporânea. 
Nesse sentido, para além do necessário trabalho coletivo que transcenda as tradicionais divisões disciplinares, a perspectiva de Braudel em torno de uma pluralidade de tempos permanece extremamente útil. Apesar de sua interpretação das dinâmicas naturais serem fruto de seu tempo, como aponta Dipesh Chakrabarty, ainda assim, ao não tratar a natureza como simples pano de fundo, Braudel apontava para caminhos possíveis de incorporação do meio ambiente na análise. O problema em sua formulação original era que a determinação se dava de modo cíclico, os ciclos da natureza afetando a humanidade. Nossa época, no entanto, produziu uma enorme imprevisibilidade em tais processos (algo que ainda não estava evidente por ocasião da publicação do Mediterrâneo), com implicações devastadoras para o presente e o futuro da humanidade. A crise ambiental, é claro, está profundamente articulada à crise econômica, política e sociocultural que estamos vivenciando em escala global no presente. Braudel, Wallerstein e toda a tradição que temos mencionado aqui oferecem instrumentos extremamente ricos para que possamos compreender onde estamos e para onde vamos.

A. M.: Quais os desafios para se realizar uma história sobre as desigualdades em escala global?

T. P., L. M.: Os desafios são muitos. Um dos principais é conseguir construir debates interdisciplinares que imprimam a dimensão histórica em fenômenos contemporâneos de desigualdade e transcendam as amarras do nacionalismo metodológico, tão arraigado nas ciências sociais até os dias de hoje.

Como dissemos anteriormente, boa parte dos debates sobre desigualdades conduzidos por economistas é marcado pelo foco em tempos curtos e médios. Historiadores econômicos, por sua vez, apesar de visões de mais longa duração, desenvolvem boa parte das análises nos marcos de um forte nacionalismo metodológico. Em geral, buscam um fator essencial do crescimento (direitos de propriedade bem definidos, maior participação política da população etc.) para, então, construir um receituário a ser seguido por estados interessados em se desenvolver. 0 foco recai sobre dinâmicas internas, o que se reflete tanto em interpretações históricas quanto em receitas prontas para se eliminar desigualdades contemporâneas, como se essas mudanças dependessem exclusivamente de medidas tomadas na esfera política nacional.

Processos sistêmicos - e, com eles, a própria ideia de capitalismo - são descartados ou naturalizados. Seus pressupostos dificilmente são objeto de discussão. Em alguma medida, alguns dos debates de meados do século passado continuam presentes, em versões 2.0 das antigas teorias da modernização. No entanto, se a reificação da ideia de crescimento econômico e desenvolvimento já era problemática na época da Guerra Fria, como apontavam Wallerstein e muitos outros, hoje ela é simplesmente mortal. o colapso ambiental e suas implicações extremas para a vida humana obrigatoriamente nos forçam a pensar estratégias que transcendam os limites dos estados nacionais. Voltando a um ponto no qual já tocamos, será necessário pensar as estruturas que nos trouxeram até aqui. Trabalhos coletivos, para além das fronteiras disciplinares e da própria academia, são fundamentais. Felizmente, eles estão acontecendo. A nossa esperança é que o Centro UFF contribua para seu aprofundamento. 


\section{AUTOR}

\section{ANGÉLICA MÜLLER}

Professora de história do Brasil República da Universidade Federal Fluminense (Rio de Janeiro Brasil) e pesquisadora-associada do CHS/Paris 1. Bolsista produtividade do CNPq e Jovem Cientista do nosso estado Faperj. Atualmente é editora da revista Tempo e membro do Comitê de redação internacional da revista IdeAs. 